\title{
Endothelial markers in malignant vascular tumours of the liver: Superiority of QB-END/10 over Von Willebrand factor and Ulex europaeus agglutinin 1
}

\author{
P P Anthony, P Ramani
}

\begin{abstract}
A new monoclonal antibody, QB-END/ 10 , raised against the $C D 34$ antigen in human endothelial cell membranes and haemopoietic progenitor cells, was studied for its usefulness as a marker of neoplastic vascular cells in 21 angiosarcomas and seven malignant haemangioendotheliomas of the liver. QB-END/ 10 was both more sensitive and more specific than Von Willebrand factor (VWF) and Ulex europaeus 1 agglutinin (UEA-1) in labelling endothelial cells and it did not cross react with epithelia as UEA-1 often does. Staining was uniformly strong and clear in all histological variants of these two tumours. QB-END/10 should prove particularly useful in the differential diagnosis of malignant vascular tumours of the liver.
\end{abstract}

Blood vessels are not formed solely of one type of cell or tissue constituent. Their walls are made up of endothelial cells, smooth muscle, pericytes and collagen fibres of several types, mainly those found in basement membranes. Vessels are intimately bound to tissues with which they share many of these components. The intricacy of vascular structures and their interdependence with other body constituents are complicated even further when tumours arise. ${ }^{1}$

Endothelial cells, however, are an invariable component of vessels and, indeed, are unique to them. The first major advances in their identification occurred when characteristic ultrastructural features-namely, micropinocytotic vesicles, Weibel-Palade bodies, and investment by a basal lamina-were recognised. This led to the reclassification of poorly understood tumours such as intravascular broncho-alveolar tumour of the lung ${ }^{2}$ and "histiocytoid" or "epithelioid" tumours of skin $^{3}$ and liver ${ }^{4}$ as being of vascular origin. Electron microscopy, however, requires freshly collected and specially prepared tissue whereas immunocytochemistry is applicable to routine material. Antisera have therefore been raised against several antigens recently, with claims for their usefulness as endothelial markers. These include Von Willebrand factor $(\mathrm{VWF})^{56}$ formerly designated as factor VIII related antigen, and blood group isoan- tigens, ${ }^{7}$ but there are problems with both. ${ }^{8}$ Ulex europaeus agglutinin 1 (UEA-1) binds specifically to glycoproteins and glycolipids in endothelial cells, ${ }^{9}$ but these are also found in red blood cells and epithelia of ABH blood group secretors. ${ }^{10}$ Several monoclonal antibodies against endothelial cell specific antigens have been reported but so far only two, thrombomodulin ${ }^{11}$ and BMA $120,{ }^{12}$ have been found to work in formalin fixed, paraffin wax embedded tissues, and the search for others continues.

A family of seven monoclonal antibodies against CD34 was assessed recently by a group of workers. ${ }^{13-15}$ This is a 110 kilodalton glycoprotein present in haemopoietic progenitor cells and endothelial cells where it may function as an adhesion molecule. Immunoelectron microscopical examination of umbilical artery and breast and kidney capillary vessels has shown that CD34 is concentrated on membrane processes which interdigitate between endothelial cells. CD34 messenger RNA has also been shown in extracts of umbilical vein endothelial cells, in tissue culture of the same, and in vessels of the breast, kidney, and placenta. CD34 has been purified, cloned, and sequenced and it shows no homology with any known protein including VWF, nor with UEA-1. QB-END/10 (previously named 188.27) is one of these anti-CD34 antibodies. ${ }^{16}$ It is an IgG molecule and binds to endothelial cells of both lymphatic and vascular origin, retaining this property after formalin fixation and paraffin wax embedding. QB-END/10 has been released for research purposes by Quantum Biosystems, Cambridge, England, and we are grateful to Dr N Bradley for a supply to evaluate its usefulness in malignant vascular tumours of the liver by comparison with VWF and UEA-1: the results from the basis of this report.

\section{Methods}

Slides from 28 liver tumours, which had been fixed in formalin and embedded in paraffin wax, were obtained from 21 cases of angiosarcoma and seven cases of malignant epithelioid haemangioendothelioma (MEH). Sixteen of the 21 cases of angiosarcoma formed part of a continuing survey conducted by the Angiosarcoma Register of the Employment Medical
Correspondence to: Professor PP Anthony. Accepted for publication 16 August 1990 
Figure 1 Angiosarcoma: "papillae" of liver cell plates protrude into a cystic space: they are covered by positively stained tumour cells in a "tectorial" manner (Avidin-biotin $/ Q B$ END).
Advisory Service of the Health and Safety Executive (courtesy of Dr K Campion). Six were associated with previous exposure to thorium dioxide (Thorotrast) and two to vinyl chloride monomer. All diagnoses had been agreed by a panel of pathologists (PP Anthony, RNM MacSween, and PJ Scheuer). Five were referred for consultation and were diagnosed by the same criteria. Of seven cases of $\mathrm{MEH}$, one came from the Angiosarcoma Register, two from personal experience, and four had been referred for consultation. All seven had been previously investigated and diagnosed by published criteria, four by more than one expert liver pathologist.

Archival material, stained by haematoxylin and eosin, Gordon \& Sweet's reticulin, periodic acid Schiff reagent and, in some cases, by VWF or UEA-1, was re-examined.

A polyclonal rabbit antibody to VWF (Dakopatts) was used at a 1 in 400 dilution. UEA-1 (Dakopatts) was used at a dilution of 1 in 400 and rabbit anti-UEA-1 (Dakopatts) at a dilution of 1 in 300 . Biotinylated swine antirabbit antibody (Dakopatts) was used as a

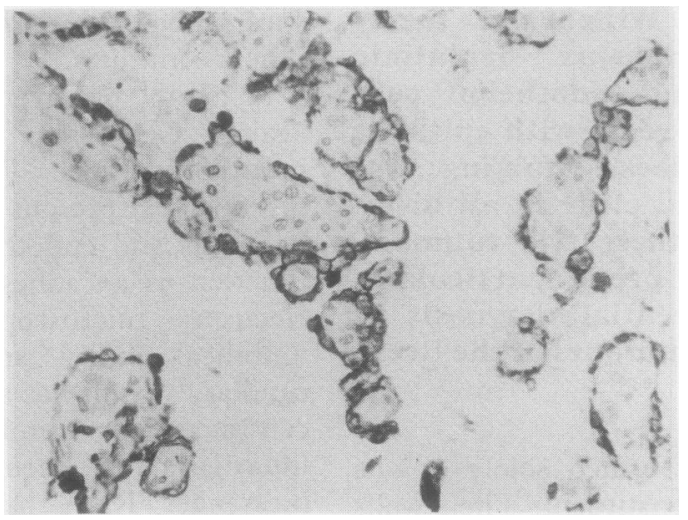

bridging layer for the above primary antibodies. Monoclonal mouse antibody QBEND/10 (Quantum Biosystems) was used at a dilution of 1 in 300. Biotinylated rabbit antimouse antibody (Dakopatts) was used as a second layer at a dilution of 1 in 200. Peroxidase conjugated avidin (Dakopatts) was used at a dilution of 1 in 500 .

Paraffin wax sections were cut at 3-4 $\mu \mathrm{m}$ and stained by a modification of the avidinbiotin complex method described by Guesdon et al. ${ }^{17}$ Briefly, sections were waxed and taken to industrial methylated spirit. Endogenous peroxidase was blocked with $\mathrm{H}_{2} \mathrm{O}_{2}$ in methanol. Sections to be stained for UEA-1 in VWF were treated with trypsin (Sigma) for 10 minutes, followed by 30 minutes' incubation with normal swine serum. Sections were washed in running tap water and placed in TRIS-buffered saline (TBS) at pH 7·6. Sections were incubated with successive antibodies between washes with TBS, followed by development of the reaction product with diaminobenzidine for five to 10 minutes, counterstained with Mayer's haematoxylin, and mounted. Negative controls without antibody were run in parallel. Staining of endothelium in non-neoplastic vessels served as an endogenous positive control.

\section{Results}

Positive staining was semiquantitatively assessed as + (from a few to one third of tumour cells positive), ++ (around half of cells positive), and +++ (from two thirds to all cells positive). The results are shown in the table. These were then averaged to arrive at an overall score.
Figure 2 Malignant epithelioid

haemangioendothelioma. (A) Clearly stained strands and tubular structures infiltrate the liver (avidin-biotin $/ Q B$ END). (B) A tongue-like portal intravascular tumour growth is stained strongly: note the unstained bile duct nearby (avidin-biotin $/ Q B$ END). (C) Small groups of tumour cells, embedded in a myxohyaline stroma, display positively stained intracytoplasmic lumina (avidin-biotin $\mid Q B-$ END).

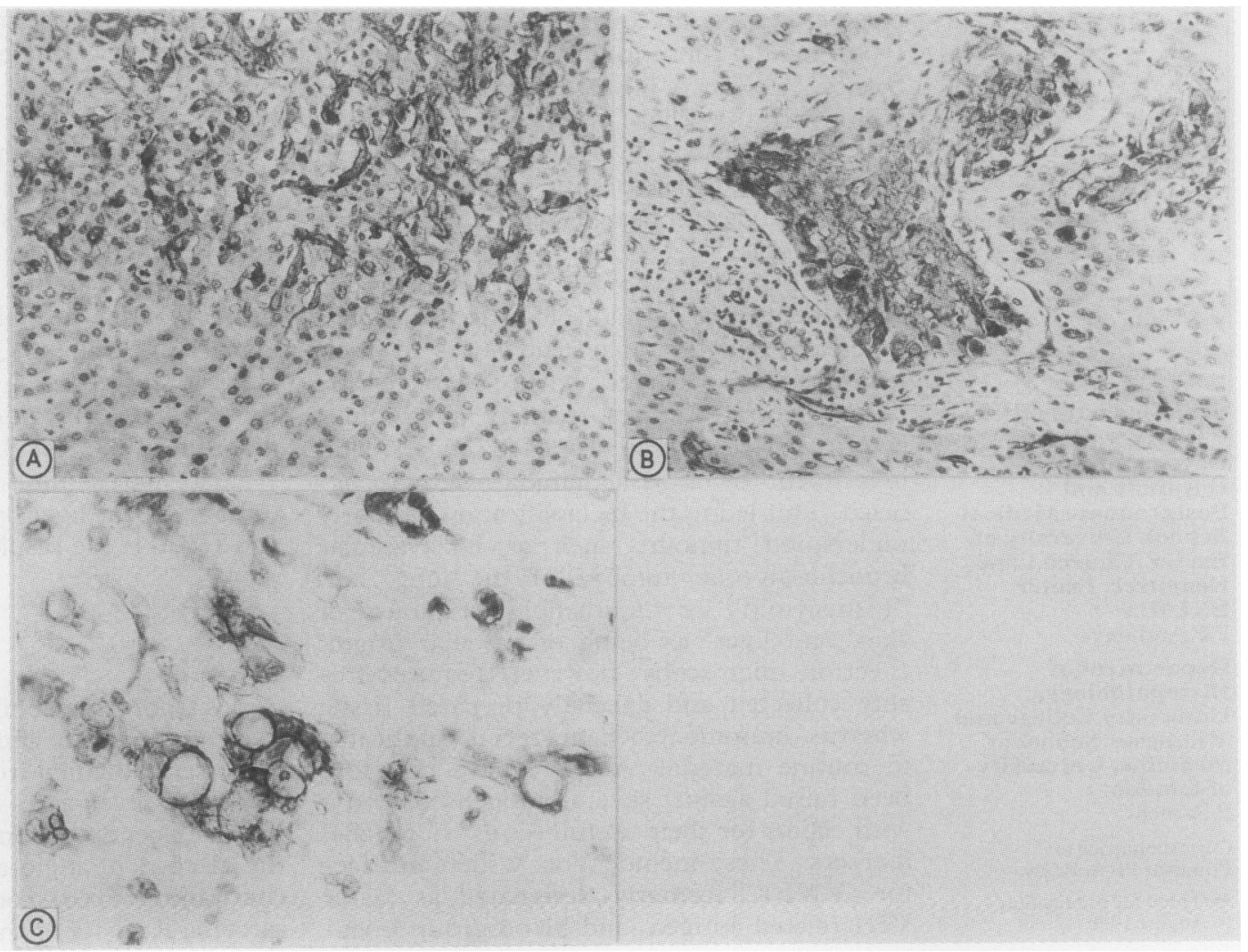


Semiquantitative results of staining angiosarcomas and malignant haemangioendotheliomas of liver by three endothelial markers

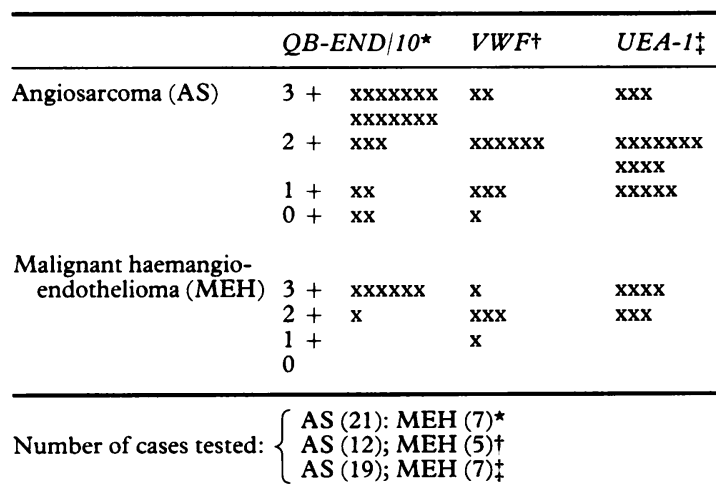

QB-END/10 stained crisply and uniformly 14 of 21 cases of angiosarcoma and six of seven cases of malignant haemangioendothelioma, with overall scores of 2.38 and $2 \cdot 85$, respectively. Four cases of angiosarcoma stained poorly; this seemed to be associated with lack of fixation and post mortem autolysis. In well fixed and preserved tumours, cells stained well in "classic" areas (tumour cells covering liver cell plates in a "tectorial" manner, as well as in less typical arrangements-solid masses or "cysts" lined by 'papillae' (fig 1). All cases of malignant haemangioendothelioma stained well throughout (overall score $2 \cdot 85$ ) as strands or tube-like structures infiltrating the liver sinusoids (fig $2 \mathrm{~A}$ ), or as tongue-like projections within vessels (fig 2B). Intracytoplasmic lumina in small groups of tumour cells were also readily shown (Fig 2C).

VWF stained angiosarcoma moderately, with an overall score of 1.83 ; only two cases reacted well and one not at all. Staining was

Figure 3 Angiosarcoma: granular staining of tumour cells in a solid area (avidin-biotin/VWF).
Figure 4 Angiosarcoma: irregular and variably staining vascular structures contrast with strongly reacting bile ducts (avidin-biotin/UEA-1).
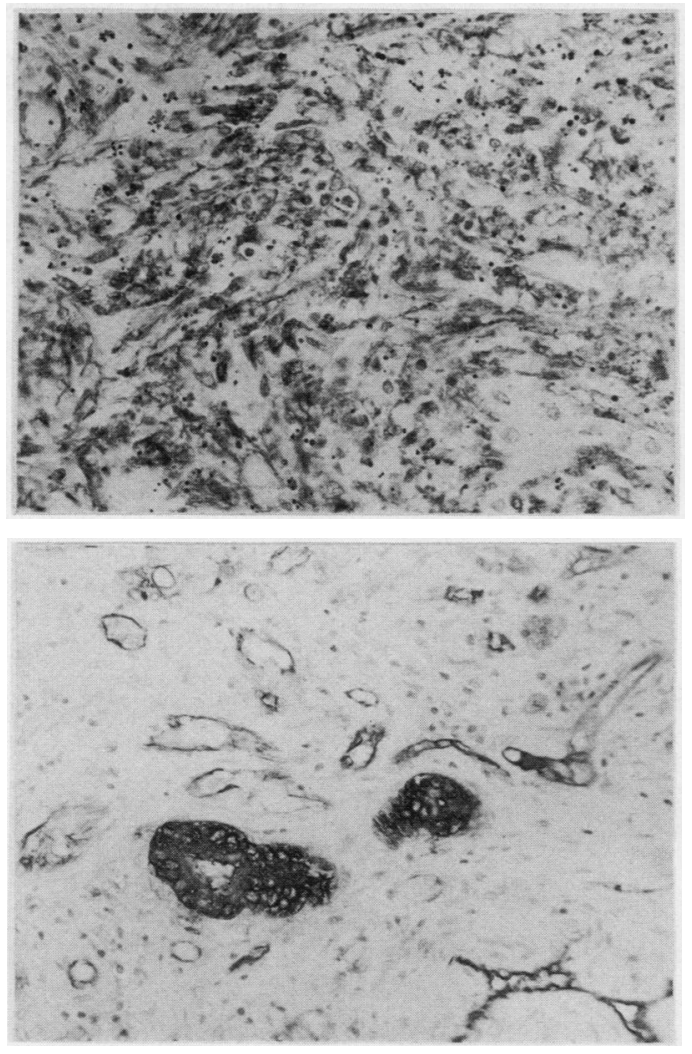

generally patchy and granular and was best seen in solid areas (fig 3). Malignant haemangioendotheliomas reacted somewhat better, with a score of $2 \cdot 0$; staining was again patchy.

UEA-1 performed as well as VWF in angiosarcomas with an average score of 1.89 , and very well in malignant haemangioendotheliomas with a score of $2 \cdot 57$. Staining was crisp in all histological patterns of these two tumours. In 16 of 26 cases tested, however, bile duct epithelium or blood cells also stained strongly (fig 4).

\section{Discussion}

Malignant vascular tumours of the liver are rare, but they are the commonest sarcomas at this site and they have attracted much interest recently for two main reasons. ${ }^{18}$ One concerns aetiology. The main known aetiological agent of "classic" angiosarcoma is thorium dioxide (Thorotrast), a radiological contrast medium, that has been in use since the late 1920s: it is radioactive and emits alpha particles over the lifetime of those exposed to it. The peak incidence may have been passed but new cases continue to appear. The number of people at risk is unknown but it was estimated to be between 50,000 and 100,000 not long ago. ${ }^{19}$ Occupational exposure to vinyl chloride monomer is next in importance. The discovery of this hazard in the early 1970 s led to the establishment of survey schemes and registers in the United States, Germany, Great Britain and more recently, in Japan. Other agents, like arsenic, copper in vintner's sprays, and rarely, drugs, are of much lesser importance. ${ }^{18}$ Angiosarcoma of the liver is therefore one of the most important examples of a malignant tumour induced by medical treatment and by industrial exposure to a known agent.

The second reason for continuing interest is difficulty in diagnosis: only one third of the cases submitted to the Angiosarcoma Panel of the Health and Safety Executive were confirmed. ${ }^{20}$ The same applies even more to malignant haemangioendothelioma. This tumour produces such variability in histological appearance that almost no two cases are exactly alike and new features of it continue to be described..$^{21}$ Recognition is important as amenability to treatment is greater and prognosis is better than is the case for either angiosarcoma or other malignant tumours of the liver.

Immunocytochemistry, using antibodies raised against antigens associated with endothelial cells, is the mainstay of diagnosis in difficult cases, given the variability of histological appearances by routine, empirical methods and the need for fresh tissue for electron microscopy. Von Willebrand factor is the most commonly looked for antigen but results have been variable or poor due to weak and patchy positive reaction. Most studies concluded that it was a reasonably specific but insensitive marker. ${ }^{82-24}$ These findings have been confirmed in this study. Lectin cytochemistry, using UEA-1 as a marker, is much more sensitive but also less specific, and cross 
reaction with epithelia has been recorded by most authors. ${ }^{1022-24}$ UEA-1 binds specifically to an oligosaccharide component of the $\mathrm{ABO}$ blood group, antigen $\mathrm{H}$, found in red blood cells and secretory epithelia of group 0 subjects. This cross reaction was found in 16 of 26 cases in this study and, given the fact that malignant haemangioendothelioma may mimick an adenocarcinoma in appearance, it greatly diminishes its usefulness as an endothelial marker. Indeed, before the entity was recognised examples were regarded as "sclerosing cholangio-carcinomas".

QB-END/10 avoids most of the difficulties encountered with VWF and UEA-1 and is both specific and sensitive. All histological patterns of angiosarcoma and malignant haemangioendothelioma have been shown to stain clearly and well. For the time being and until more experience has been gained, however, it would be wise to use QB-END/10 in conjunction with VWF and UEA-1, but, in this study at least, QB-END/10 has proved superior to both.

We are grateful to Drs $S$ Watts and $H$ Molgaard for advice on the nature of CD34 and the antibodies raised against it, and we thank Mr K Miller and Miss R Baines for technical support and Mrs G Marshall for secretarial assistance.

QB-END/10 is now marketed by Serotec, 22 Bankside, Station Approach, Kidlington, Oxford OX5 1JE UK.

1 Ashley DJB. Tumours of the vascular system. In: Anthony PP, MacSween RNM, eds. Recent advances in histopathology. Vol 13. Edinburgh: Churchill Livingstone 1987: ology.

2 Corrin B, Manners B, Millard M, Weaver L. Histogenesis of the so-called "intravascular bronchoalveolar tumour". $J$ Pathol 1979;128:163-7.

3 Weiss SW, Enzinger FM. Epithelioid haemangioendothelioma. Cancer 1982;50:970-81.

4 Ishak KG, Sesterhenn IA, Goodman ZD, Rabin L, Stromeyer FW. Epithelioid haemangioendothelioma of the liver. Hum Pathol 1984;15:839-52.

5 Bukh A, Ingersher J, Stenbjerg S, Miller NPH. The multimeric structure of plasma $F$ VIII RAg studied by electroelution and immunoperoxidase detection. Thromb Res 1986;43:579-84.

6 Mukai K, Rosai J, Burgdorf WHC. Localisation of factor VIII related antigen in vascular endothelial cells using an immunoperoxidase method. Am J Surg Pathol 1980; immunop

7 Berry CL, Amerigo J. Blood group antigens in vascular tumours: evaluation of the immunoperoxidase technique. Virchows Arch (Pathol Anat) 1980;388:167-74.

8 Stephenson TJ, Mills PM. Monoclonal antibodies to blood group isoantigens: alternative marker to factor VIII related antigen for benign and malignant vascular endothelial cells. J Pathol 1985;147:139-48.

9 Miettinen M, Holthofer H, Lehto V-P, Miettinen A Virtanen I. Ulex europaeus 1 lectin as a marker for tumours derived from endothelial cells. Am J Clin Pathol 1983;79:32-6.

10 Torrado J, Blasco E, Cosme A, Gutierrez-Hoyoz A, Arenas JI. Expression of type 1 and type 2 blood group related antigens in normal and neoplastic gastric mucosa. $A m \mathrm{~J}$ Clin Pathol 1989;91:249-54.

11 Yonezawa S, Maruyama I, Sakae K, et al. Thrombomodulin as a marker for vascular tumours. Am J Clin Pathol 1987;88:405-11.

12 Alles JU, Bosslet K. Immunocytochemistry of angiosarcomas. A study of 19 cases with special emphasis on the applicability of endothelial cell markers to routinely prepared tissues. Am J Clin Pathol 1988;89:463-71.

13 Watt SM, Karhi K, Gatter K, et al. Distribution and epitope analysis of the cell membrane glycoprotein (HPCA-1) associated with human hemopoietic cells. Leukaemia 1987;1:417-26.

14 Sutherland R, Watt SM, Dowden G, et al. Structural and partial amino acid sequence analysis of the human hemopoietic progenitor cell antigen CD34. Leukaemia 1988;2:793-803.

15 Fina L, Molgaard HV, Robertson D, et al. Expression of the CD34 gene in vascular endothelial cells. Blood 1990;75: 2417-26.

16 Civin CI, Trischmann TM, Fackler MJ, et al. Report on the CD34 cluster workshop. In: Knapp W, Dörken B, Gilks WR, et al. eds. Leucocyte typing IV. White cell differentiation antigens. Oxford: Oxford University Press, 1989: tion antig-25.

17 Guesdon JL, Tern T, Avrameas S. The use of avidin-biotin interaction in immunoenzymatic technique. $J$ Histochem interaction in immunoenzy
Cytochem 1979;27:1131-9.

18 Zafrani ES. Update on vascular tumours of the liver. $J$ Hepatol 1989;8:125-30.

19 Selinger M, Koff RS. Thorotrast and the liver, a reminder. Gastroenterology 1975;68:799-803.

20 Baxter PJ, Anthony PP, MacSween RNM, Scheuer PJ. Angiosarcoma of the liver in Great Britain, 1963-1973. BrMed J 1977;ii:919-21.

21 Dietze O, Davies SE, Williams R, Portmann B. Malignant epithelioid haemangioendothelioma of the liver: a clinicopathological and histochemical study of 12 cases. Histopathology 1989;15:225-37.

22 Little D, Said JW, Siegel RJ, Fealy M, Fishbein MC. Endothelial cell markers in vascular neoplasms: an immunohistochemical study comparing factor VIIIrelated antigen, blood group specific antigens, 6-KetoPGF1 Alpha and Ulex europaeus 1 lectin. J Pathol 1986;149:89-95.

23 Leader M, Collins M, Patel J, Henry K. Staining for factor VIII related antigens and Ulex europaeus agglutinin 1 (UEA-1) in 230 tumours. An assessment of their specificity for angiosarcoma and Kaposi's sarcoma. Histopathology 1986;10:1153-62.

24 Hultberg BM, Dangaard S, Johansen HF, Mouridsen HT Hou-Jensen K. Malignant haemangiopericytomas and haemangioendotheliosarcomas: an immunohistochemical haemangioendotheliosarcomas: an imm
study. Histopathology 1988;12:405-14. 